\title{
Comparative adrenal suppression with inhaled budesonide and fluticasone propionate in adult
} asthmatic patients

\author{
D J Clark, A Grove, R I Cargill, B J Lipworth
}

\begin{abstract}
Background - A study was performed to compare the adrenal suppression caused by inhaled fluticasone propionate and budesonide on a microgram equivalent basis, each given by metered dose inhaler to asthmatic patients.
\end{abstract}

Methods - Twelve asthmatic patients of mean age 29.9 years, with a forced expiratory volume in one second $\left(\mathrm{FEV}_{1}\right)$ $92.9 \%$ predicted and forced expiratory flow $25-75 \%\left(\mathrm{FEF}_{25-75}\right) 69 \cdot 5 \%$ predicted, on less than or equal to $400 \mu$ g/day inhaled corticosteroid, were studied in a double blind placebo controlled crossover design comparing single doses of inhaled budesonide $400,1000,1600,2000 \mu \mathrm{g}$ and fluticasone propionate 500, 1000, 1500, $2000 \mu \mathrm{g}$. Doses were administered at 22.00 hours by metered dose inhaler with mouth rinsing and measurements were made in the laboratory 10 hours later.

Results - Serum cortisol levels compared with placebo (mean $325.2 \mathrm{nmol} / \mathrm{l}$ ) were suppressed by fluticasone at doses of $1500 \mu \mathrm{g} \quad(211.6 \mathrm{nmol} / \mathrm{l})$ and $2000 \mu \mathrm{g}$ $(112 \cdot 3 \mathrm{nmol} / \mathrm{l})$ and by budesonide at $2000 \mu \mathrm{g}$ (243.4 nmol/1). Fluticasone propionate $2000 \mu \mathrm{g}$ produced lower absolute serum cortisol levels than budesonide $2000 \mu \mathrm{g}$ (95\% CI for difference 42.9 to 219.2$)$. The dose ratio (geometric mean) for the relative potency was 2.89 fold $(95 \%$ CI 1.19 to 7.07). In terms of percentage suppression versus placebo, fluticasone propionate also produced greater effects (means and 95\% CI for difference): budesonide $1600 \mu \mathrm{g}$ $(\mathbf{1 6 . 0 )}$ versus fluticasone propionate $1500 \mu \mathrm{g}(40.9)(95 \% \mathrm{CI}-0.6$ to 50.6$)$, budesonide $2000 \mu \mathrm{g}(26 \cdot 0)$ versus fluticasone $2000 \mu \mathrm{g}(65 \cdot 2)(95 \% \mathrm{CI} 10 \cdot 5$ to $67 \cdot 8)$. Individual serum cortisol levels at the two highest doses showed 15 of 24 patients below the normal limit of the reference range $(150 \mathrm{nmol} / 1)$ for fluticasone and five of 24 for budesonide. Fluticasone propionate also caused greater ACTH suppression than budesonide (as \% versus placebo): budesonide $1600 \mu \mathrm{g}(12 \cdot 0)$ versus fluticasone propionate $1500 \mu \mathrm{g}(31.9)(95 \%$ CI 7.6 to $32 \cdot 1)$, budesonide $2000 \mu \mathrm{g}(13.5)$ versus fluticasone propionate $2000 \mu \mathrm{g}$ $(44 \cdot 4)(95 \%$ CI $13 \cdot 2$ to $48 \cdot 7)$. For overnight 10 hour urinary cortisol (nmol/10 hours) there was a difference between the lowest doses of the two drugs: budesonide $400 \mu \mathrm{g}$
$(37 \cdot 2)$ versus fluticasone propionate $500 \mu \mathrm{g}$ (19.9) (95\% CI 6.9 to $27 \cdot 8)$.

Conclusions - Like budesonide the systemic bioactivity of fluticasone propionate is mainly due to lung vascular absorption. Fluticasone propionate exhibited at least twofold greater adrenal suppression than budesonide on a microgram equivalent basis in asthmatic patients.

(Thorax 1996;51:262-266)

Keywords: adrenal suppression, inhaled corticosteroids, asthma, fluticasone propionate, budesonide.

Inhaled corticosteroids are now widely accepted as first line preventive treatment in asthma. ${ }^{1}$ Increasing use is being made of high dose inhaled corticosteroids during the stepup phase of treatment in order to optimise asthma control. Surprisingly, no dose ranging studies have been performed to compare the systemic bioactivity of different inhaled corticosteroids.

The risk to benefit ratio for inhaled corticosteroids comprises their relative potencies for airway and systemic glucocorticoid activity. There have been varying estimates of topical glucocorticoid activity as assessed by the MacKenzie skin vasoconstrictor assay, although it is generally accepted that fluticasone propionate is at least twice as potent as budesonide and beclomethasone dipropionate. ${ }^{2-4}$ Systemic effects of inhaled corticosteroids may arise from absorption from either the gastrointestinal tract or the lung. ${ }^{5}$ Since a large proportion of the dose from a metered dose inhaler is deposited in the oropharynx, it is therefore available for gastrointestinal absorption after swallowing. First pass hepatic metabolism is estimated at $99 \%$ for fluticasone propionate and $89 \%$ for budesonide. ${ }^{67}$ Thus, assuming approximately $20 \%$ lung deposition for a metered dose inhaler, ${ }^{8}$ the main determinant of overall systemic bioactivity will be the lung bioavailability which avoids first pass hepatic metabolism for both budesonide and fluticasone propionate. ${ }^{5}$ Indeed, this was found to be the case in a previous chronic dosing study in normal subjects where $800 \mu \mathrm{g} /$ day budesonide dry powder inhaler (Turbohaler) and $750 \mu \mathrm{g} /$ day fluticasone propionate dry powder inhaler (Diskhaler) caused equivalent suppression of the tetracosactrin response even when taken in conjunction with mouth rinsing. ${ }^{9}$ However, it was hypothesised that, when taking into account the confounding effects of different lung deposition with the dry powder de- 
vices, fluticasone propionate probably exhibits greater systemic bioactivity than budesonide on a microgram equivalent basis.

The aim of this study was therefore to extend previous observations in normal subjects in a dose ranging comparison of adrenal suppression with fluticasone propionate and budesonide on a microgram equivalent basis, both taken with metered dose inhalers.

\section{Methods \\ PATIENTS}

Twelve asthmatic patients (five women) of mean (SE) age $29.9(2.5)$ years completed the study. The mean forced expiratory volume in one second $\left(\mathrm{FEV}_{1}\right)$ was $3.48(0.23) 1,92.9$ $(4.5) \%$ of predicted, and forced expiratory flow $25-75 \%\left(\mathrm{FEF}_{25-75}\right)$ was $3.09(0.36) \mathrm{l} / \mathrm{s}, 69.5$ $(7 \cdot 9) \%$ of predicted. Haematological and biochemical parameters were normal prior to entry into the study. All gave written informed consent having obtained approval from the Tayside medical ethics committee. All patients had asthma according to the criteria of the American Thoracic Society ${ }^{10}$ and were required to be taking equal to or less than $400 \mu \mathrm{g} /$ day inhaled corticosteroid. Of the 12 subjects 11 were inhaling corticosteroid (beclomethasone dipropionate) in doses of $100 \mu \mathrm{g}$ (four patients), $200 \mu \mathrm{g}$ (three patients), $300 \mu \mathrm{g}$ (one patient), and $400 \mu \mathrm{g}$ (three patients). None had received oral corticosteroids during the preceding three months.

\section{STUDY DESIGN}

A double blind, placebo controlled, randomised (Latin square) crossover design was used. Subjects attended an initial screening visit where $\mathrm{FEV}_{1}$ and $\mathrm{FEF}_{25-75}$ were measured using a Vitalograph compact spirometer (Vitalograph Ltd, Buckingham, UK), having withheld inhaled bronchodilators for eight

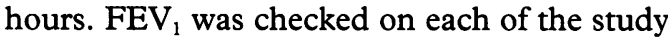
visits and measurements were only made if it was within $15 \%$ of the baseline value. Inhaler technique was assessed using an aerosol inhalation monitor (Vitalograph Ltd) and detailed instructions in correct usage were given at each visit. Subjects were then randomised to receive fluticasone propionate (Flixotide metered dose inhaler, $250 \mu \mathrm{g}$ per actuation, Allen and Hanburys, Middlesex, UK) in doses of $500 \mu \mathrm{g}, 1000 \mu \mathrm{g}, 1500 \mu \mathrm{g}$, or $2000 \mu \mathrm{g}$, budesonide (Pulmicort metered dose inhaler, $200 \mu \mathrm{g}$ per actuation, Astra Pharmaceuticals, Herts, UK) in doses of $400 \mu \mathrm{g}, 1000 \mu \mathrm{g}$, $1600 \mu \mathrm{g}$, or $2000 \mu \mathrm{g}$, or placebo metered dose inhaler, each as a single dose, at 22.00 hours on the evening before each laboratory visit. The aerosol cannisters and plastic actuators were masked and placed in identical boxes to blind the treatment to the patient. Each treatment box was dispensed by a different person from the investigator to make the study double blind. Each of the nine study visits was separated by a washout period of at least three days. Subjects omitted their usual steroid inhaler on each study day and took their bronchodilator inhaler 15 minutes before the study drug in the evening. Mouth rinsing was performed after each two puffs of their study inhaler. Before taking the study drug subjects emptied their bladder and collected all their overnight urine for 10 hours until the laboratory visit the following morning. No further steroid or bronchodilator inhalers were taken until completion of the laboratory visit.

\section{MEASUREMENTS}

The subjects attended the laboratory at 08.00 hours, 10 hours after taking the study drug. A cannula was inserted into an antecubital fossa vein to allow blood sampling, and subjects then rested supine for 30 minutes. After the rest period blood samples were taken for measurement of serum cortisol and plasma adrenocorticotrophic hormone (ACTH) levels. The total volume of the overnight 10 hour urine specimen was measured, with aliquots kept for assay of cortisol levels.

\section{ASSAYS}

Serum and urinary cortisol levels were measured using a commercial radioimmunoassay kit (Incstar, Wokingham, Berkshire, UK). The coefficient of variability for analytical imprecision within the assay was $9.4 \%$. The lower limit for the normal reference range of serum cortisol levels in our laboratory is $150 \mathrm{nmol} / \mathrm{l}$. Plasma levels of ACTH were measured using a commercial immunoradiometric assay (Incstar, Wokingham, Berkshire, UK). The coefficient of variability for analytical imprecision within the assay was $3 \cdot 54 \%$.

\section{DATA ANALYSIS}

All data were analysed using a Statgraphics software package (STSC Software Group, Rockville, Maryland, USA). The primary comparison was between treatments at each dose level - that is, fluticasone propionate $500 \mu \mathrm{g}$ $v$ budesonide $400 \mu \mathrm{g}$, fluticasone propionate $1000 \mu \mathrm{g} v$ budesonide $1000 \mu \mathrm{g}$, fluticasone propionate $1500 \mu \mathrm{g} v$ budesonide $1600 \mu \mathrm{g}$, fluticasone propionate $2000 \mu \mathrm{g} v$ budesonide $2000 \mu \mathrm{g}$. A secondary comparison was made within each treatment group versus placebo that is, fluticasone propionate $500,1000,1500$, and $2000 \mu \mathrm{g}$ and budesonide 400,1000, 1600 and $2000 \mu \mathrm{g}$ versus placebo. Comparisons were made by multifactorial analysis of variance (MANOVA) using subjects, treatments, and doses as within factors. Where the overall MANOVA was significant, Duncan's multiple range testing with $95 \%$ confidence limits was used in order to define where these differences were significant. A probability level of $p<0.05$ (two tailed) was considered to be significant for all tests. For the primary comparison between treatments the $95 \% \mathrm{CI}$ for mean differences were also calculated where a significant difference was detected. For comparison of the proportion of individual cortisol values below the normal reference range the $\chi^{2}$ test was used. 


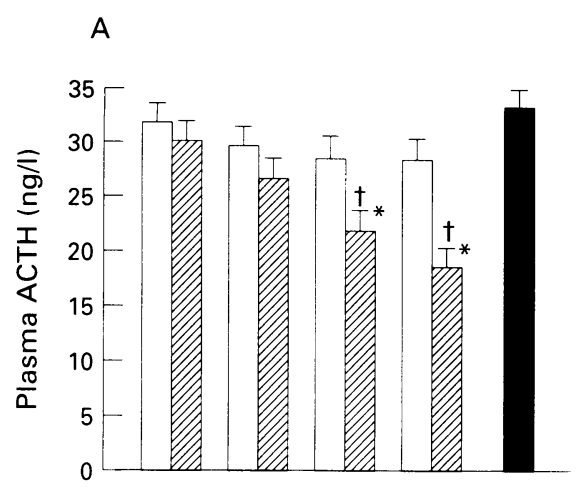

B

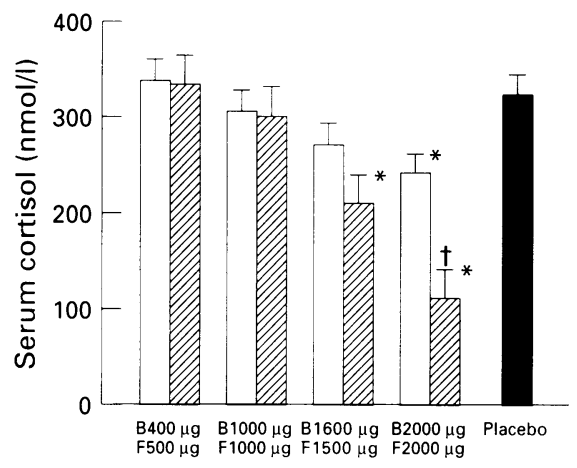

C

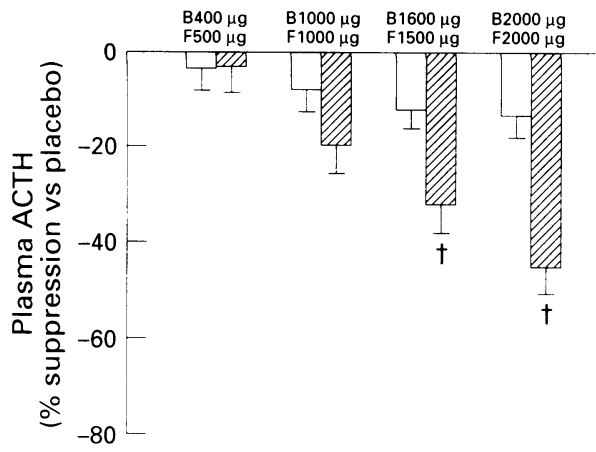

D

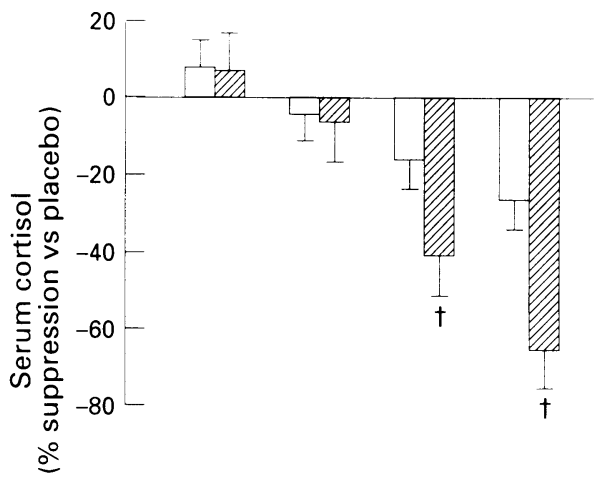

Figure 1 Mean (SE) plasma ACTH (A) and serum cortisol (B) concentrations with single doses of budesonide (B), fluticasone $(F)$, and placebo: $\dagger p<0.05$ budesonide versus fluticasone at a given dose level; * significant difference between the steroid dose and placebo. Mean (SE) percentage suppression versus placebo for (C) plasma ACTH and (D) serum cortisol levels with single doses of budesonide (B) and fluticasone (F): $\dagger p<0.05$ budesonide versus fluticasone at a given dose level. $\square=$ budesonide; $\mathbb{Z}=$ fluticasone.

Table 1 Effects of placebo, budesonide (B), and fluticasone $(F)$ at different dose levels ( $\mu$ ) on serum cortisol and plasma ACTH levels and urinary free cortisol excretion

\begin{tabular}{lccccc}
\hline & Placebo & $B 400 / F 500$ & $B 1000 / F 1000$ & $B 1600 / F 1500$ & $B 2000 / F 2000$ \\
\hline $\begin{array}{l}\text { Serum cortisol } \\
\text { (nmol/l) }\end{array}$ & $325 \cdot 2$ & $338 \cdot 9 / 335 \cdot 4$ & $305 \cdot 4 / 302 \cdot 2$ & $271 \cdot 6 / 211 \cdot 6$ & $\begin{array}{c}243 \cdot 4 / 112 \cdot 3 * * \\
(42 \cdot 9 \text { to } 219 \cdot 2)\end{array}$ \\
$\begin{array}{l}\text { Plasma ACTH } \\
\text { (ng/l) }\end{array}$ & $32 \cdot 8$ & $31 \cdot 7 / 30 \cdot 0$ & $29 \cdot 6 / 26 \cdot 4$ & $\begin{array}{r}28 \cdot 4 / 21 \cdot 7^{*} \\
(1 \cdot 6 \text { to } 11 \cdot 9)\end{array}$ & $\begin{array}{c}(3 \cdot 0 \text { to } 16 \cdot 5) \\
26 \cdot 1 / 10 \cdot 6 * *\end{array}$ \\
$\begin{array}{l}\text { Urinary free cortisol } \\
\text { (nmol/10 hour) }\end{array}$ & $48 \cdot 6$ & $\begin{array}{l}37 \cdot 2 / 19 \cdot 9 * * \\
(6 \cdot 9 \text { to } 27 \cdot 8)\end{array}$ & $21 \cdot 0 / 23 \cdot 8$ & $\begin{array}{c}24 \cdot 5 / 9 \cdot 0^{* *} \\
(7 \cdot 4 \text { to } 23 \cdot 5)\end{array}$ & \begin{tabular}{l}
$(7 \cdot 5$ to $23 \cdot 7)$ \\
\hline
\end{tabular} \\
\hline
\end{tabular}

Values are means and $95 \%$ confidence intervals are given where the difference is significant.

${ }^{*} \mathrm{p}<0.05 ;{ }^{* *} \mathrm{p}<0.01$.

Table 2 Percentage suppression of serum cortisol and plasma ACTH levels compared with placebo for budenoside (B) and fluticasone $(F)$ at different dose levels $(\mu g)$

\begin{tabular}{|c|c|c|c|c|}
\hline & $B 400 / F 500$ & $B 1000 / F 1000$ & $B 1600 / F 1500$ & B2000/F2000 \\
\hline Serum cortisol & $-7 \cdot 5 /-6 \cdot 9$ & $4 \cdot 4 / 6 \cdot 0$ & $\begin{array}{l}16 \cdot 0 / 40 \cdot 9^{*} \\
(-0.6 \text { to } 50 \cdot 6)\end{array}$ & $\begin{array}{l}26 \cdot 0 / 65 \cdot 2^{*} \\
(10 \cdot 5 \text { to } 67 \cdot 8)\end{array}$ \\
\hline Plasma ACTH & $3 \cdot 6 / 3 \cdot 0$ & $7 \cdot 8 / 19 \cdot 6$ & $\begin{array}{l}12 \cdot 0 / 31 \cdot 9 * * \\
(7 \cdot 6 \text { to } 32 \cdot 1)\end{array}$ & $\begin{array}{l}13 \cdot 5 / 44 \cdot 4^{* *} \\
(13 \cdot 2 \text { to } 48 \cdot 7)\end{array}$ \\
\hline
\end{tabular}

Values are means and $95 \%$ confidence intervals are given where the difference is significant.

${ }^{*} \mathrm{p}<0.05 ; * * \mathrm{p}<0.01$.

\section{Results}

The mean values for serum cortisol and plasma ACTH levels compared with placebo are depicted in fig $1 \mathrm{~A}$ and $\mathrm{B}$ and table 1 . This illustrates the dose-dependent suppression of serum cortisol and plasma ACTH levels with both drugs, although the effect was greater with fluticasone propionate. The percentage suppression was similar for both cortisol and $\mathrm{ACTH}$, with a steeper dose response effect for fluticasone as shown in fig $1 \mathrm{C}$ and $\mathrm{D}$ and table 2 .
Fluticasone propionate produced significantly more suppression of morning serum cortisol levels than placebo at $1500 \mu \mathrm{g}$ and $2000 \mu \mathrm{g}$, while the levels were only suppressed significantly by budesonide at $2000 \mu \mathrm{g}$. Fluticasone $2000 \mu \mathrm{g}$ produced significantly lower absolute serum cortisol levels than budesonide $2000 \mu \mathrm{g}$. In terms of percentage suppression versus placebo, fluticasone also produced a greater effect at $1500 \mu \mathrm{g}$ and $2000 \mu \mathrm{g}$. At the $2000 \mu \mathrm{g}$ dose fluticasone propionate exhibited a 2.89 fold dose ratio (geometric mean) for 


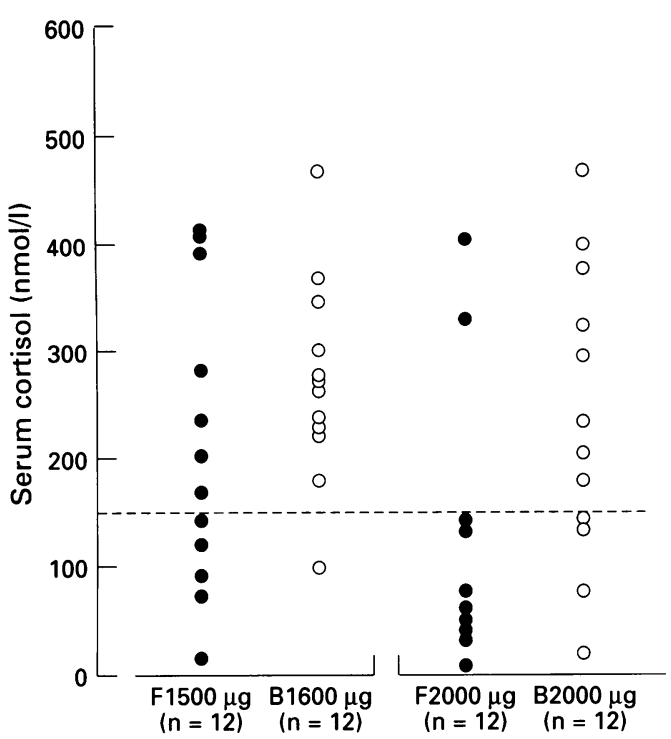

Figure 2 Individual serum cortisol values at the two highest doses of fluticasone $(F, O)$ and budesonide $(B$, O). Interrupted horizontal line represents lower limit of normal reference range for cortisol (150 nmol/l). $n=15 / 24$ below limit for fluticasone and $n=5 / 24$ below limit for budesonide $(p<0.005)$.

relative suppression versus budesonide $(95 \%$ CI $1 \cdot 19$ to $7 \cdot 07)$. Individual values for serum cortisol levels at the two highest doses showed 15 of 24 patients below the lower limit of the reference range $(150 \mathrm{nmol} / \mathrm{l})$ for fluticasone and five of 24 for budesonide ( $\mathrm{p}<0.005$; fig 2 ).

Fluticasone at $1500 \mu \mathrm{g}$ and $2000 \mu \mathrm{g}$ significantly suppressed plasma ACTH levels (ng/l) compared with placebo, while budesonide did not show significant suppression at any dose. Fluticasone produced significantly lower absolute plasma ACTH levels than budesonide at $1500 \mu \mathrm{g}$ and $2000 \mu \mathrm{g}$. In terms of percentage suppression versus placebo, fluticasone also produced a greater effect at $1500 \mu \mathrm{g}$ and $2000 \mu \mathrm{g}$.

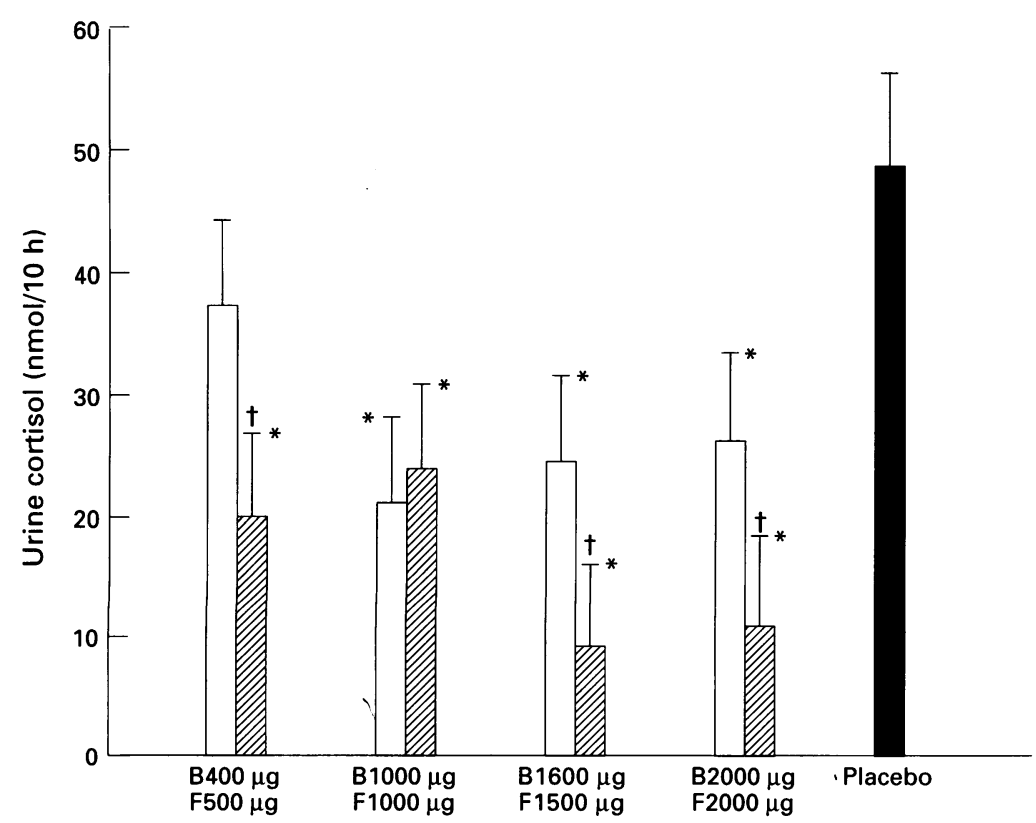

Figure 3 Mean (SE) urinary cortisol excretion with single doses of budesonide (B, $\square$ ), fluticasone $(F, \mathbb{Z})$, and placebo. $\dagger_{p}<0.05$ budesonide versus fluticasone at a given dose level; * significant difference between the steroid dose and placebo.
The urinary free cortisol (nmol/10 hours) results are illustrated in fig 3 and table 1 . All doses of fluticasone and all except $400 \mu \mathrm{g}$ budesonide showed significant suppression versus placebo. Significant differences between fluticasone and budesonide were observed at all doses except $1000 \mu \mathrm{g}$.

\section{Discussion}

The results of this study showed significant differences between fluticasone propionate metered dose inhaler and budesonide metered dose inhaler for three markers of hypothalamic pituitary adrenal axis suppression in asthmatic patients, with fluticasone propionate having at least a twofold greater suppression on a microgram equivalent basis. Indeed, on inspecting individual values for serum cortisol levels at the two highest doses it was apparent that 15 of 24 were below the lower limit of the normal reference range for fluticasone compared with five of 24 for budesonide. We felt it more relevant to compare these drugs on a microgram equivalent basis because, in everyday clinical practice, it is likely that a switch from one inhaled corticosteroid to another would be made at the same dose rather than at half the dose. Since mouth rinsing was employed, it can be concluded that the systemic bioactivity of fluticasone is, like budesonide, mainly due to lung vascular absorption.

It is perhaps not surprising that adrenal suppression was only detected at doses above $1000 \mu \mathrm{g}$ using early morning serum cortisol and ACTH levels as these are the least sensitive markers. Nonetheless, using ACTH we found significant suppression by fluticasone propionate at single doses of $1500 \mu \mathrm{g}$ and $2000 \mu \mathrm{g}$ but not with budesonide. Using urinary cortisol excretion, a more sensitive marker, fluticasone produced significant suppression at the $500 \mu \mathrm{g}$ dose compared with placebo. Indeed, it has previously been shown that urinary cortisol excretion is as sensitive at detecting adrenal suppression as integrated 20 hour plasma cortisol measurement. ${ }^{11}$ It was shown that fluticasone $500 \mu \mathrm{g}$ dry powder as a single dose produced $15 \%$ suppression of urinary cortisol and $19 \%$ suppression of integrated 20 hour plasma cortisol levels.

In a chronic dosing study reported by Grove et al in normal subjects similar doses of fluticasone propionate dry powder Diskhaler $(750 \mu \mathrm{g}, 1500 \mu \mathrm{g})$ were compared with budesonide dry powder Turbohaler $(800 \mu \mathrm{g}$, $1600 \mu \mathrm{g}$ ), each dose being given for one week with mouth rinsing. ${ }^{9}$ The degree of suppression as assessed by the tetracosactrin response was comparable for both drugs, despite a twofold difference in drug delivered to the lung with the Turbohaler (27\% deposition) compared with the Diskhaler ( $12 \%$ deposition) ${ }^{812}$ The conclusion drawn from this study was that, allowing for the confounding effect of lung deposition for the different dry powder devices, fluticasone propionate would be expected to produce greater adrenal suppression. This is in agreement with our present results which show at least twofold greater systemic bioactivity 
with fluticasone when given by the same device on a microgram equivalent basis.

The ratio of systemic bioactivity revealed in the present study can be explained by the known pharmacology of fluticasone propionate. Firstly, it has been shown by both the skin vasoconstrictor assay and inhibition of lymphocyte $T$ cell proliferation ${ }^{2}$ that fluticasone exhibits approximately $2-3$ fold greater potency at the glucocorticoid receptor. Secondly, fluticasone has a greater glucocorticoid receptor affinity than budesonide and longer glucocorticoid/receptor complex half life. ${ }^{13}$ Thus, when given by the inhaled route a steroid which is more potent with greater affinity and with no first pass metabolism in the lung would, from first principles, be predicted to give greater systemic adrenal effects.

It is important to consider the overall benefit to risk equation in terms of anti-asthmatic airway efficacy versus systemic adverse effects. Whilst our results show that greater pharmacological glucocorticoid receptor potency translates directly into greater systemic bioactivity at higher doses, there is evidence to suggest that the same relationship is not necessarily true for airways efficacy. For example, Boe et $a l^{14}$ compared fluticasone propionate $2.0 \mathrm{mg}$ daily with beclomethasone dipropionate $1.6 \mathrm{mg}$ daily and found no difference in antiasthmatic efficacy while adrenal suppression, as assessed from serum cortisol and ACTH levels, occurred only in the fluticasone group. In another comparison of $1.5 \mathrm{mg} /$ day of fluticasone propionate and beclomethasone dipropionate a mean treatment difference in peak flow rate amounting to $4 \%$ was reported. ${ }^{15}$ Finally, Ayres et $a l^{16}$ showed no differences in efficacy between $1 \mathrm{mg} /$ day and $2 \mathrm{mg} /$ day fluticasone, although both doses produced a small but significant improvement compared with budesonide $1.6 \mathrm{mg} /$ day. In contrast, serum cortisol ratios were significantly lower with fluticasone $2 \mathrm{mg} /$ day than with either budesonide $1.6 \mathrm{mg} /$ day or fluticasone $1 \mathrm{mg} /$ day. These studies clearly indicate that differences in pharmacological potency in vitro are not necessarily associated with commensurate differences in anti-asthmatic activity in vivo.

Thus, for most patients the dose response curve for airway efficacy becomes relatively flat above $1 \mathrm{mg}$, whereas the dose response curve for systemic bioactivity becomes steep above this dose. ${ }^{17}$ In other words, increasing the dose above $1 \mathrm{mg}$ may produce relatively little improvement in efficacy with a significantly greater increase in systemic effects. This dissociation in the benefit to risk ratio would be accentuated at higher doses, particularly with a steroid with greater systemic potency such as fluticasone propionate. It is nonetheless possible that some patients with reduced airways calibre would be protected against systemic effects because of reduced lung bioavailability due to attenuated deposition. ${ }^{5}$ Whilst effects on adrenal suppression were assessed with single doses of fluticasone and budesonide, it is likely that differences between the drugs would, if anything, be more pronounced during chronic dosing because of drug accumulation at steady state with the longer elimination half life of fluticasone. ${ }^{18}$

Clearly, further chronic dose ranging studies are required to define more clearly the benefit to risk ratio of fluticasone propionate compared with budesonide in patients with more severe asthma, both in terms of the step up and step down phases of treatment.

The authors wish to thank Mrs W Coutie for practical assistance in performing the biochemical assays and Mrs J Thomson for typing the manuscript.

1 British Thoracic Society. Guidelines for management of asthma: a summary. BMf 1993;306:776-82.

2 English AF, Neate MS, Quint DJ, Sareen M. Biological activities of some corticosteroids used in asthma. $A m \mathcal{F}$ Respir Crit Care Med 1994;149(Suppl):A212.

3 Anderson N, Klint S, Randwall G, Wiren JE. Equipotency of budesonide and fluticasone propionate in the vasoconstriction assay. Thorax 1994;49:422P.

4 Phillips GH. Structure-activity relationships of topically active steroids: the selection of fluticasone propionate. active steroids: the selection of fluticas
Respir Med 1990;84(Suppl A):19-23.

5 Lipworth BJ. New perspectives on inhaled drug delivery and systemic bioactivity. Thorax 1995;50:105-10.

6 Harding SM. The human pharmacology of fluticasone propionate. Respir Med 1990;84(Suppl A):25-9.

7 Ryrfedlt A, Anderson P, Edsbacker S, Tonnesson M, Davies $\mathrm{D}$, Pauwels R. Pharmacokinetics and metabolism of budesonide, a selective glucocorticoid. Eur F Respir Dis 1982; 63(Suppl 122):86-95.

8 Melchor R, Biddescome MF, Mak VHF, Short MD, Spiro SG. Lung deposition patterns of directly labelled salbutamol in normal subjects and in patients with reversible airflow obstruction. Thorax 1993;48:506-11.

9 Grove A, Allam C, McFarlane LC, McPhate G, Jackson CM, Lipworth BJ. A comparison of systemic bioactivity of inhaled budesonide and fluticasone propionate in normal inhaled budesonide and fluticasone propionate

10 American Thoracic Society. Standards for the diagnosis and care of patients with chronic obstructive pulmonary disease (COPD) and asthma. Am Rev Respir Dis 1987;136:225-43.

11 Grahnen A, Eckernas SA, Brundin RM, Ling-Andersson A. An assessment of the systemic activity of single doses of inhaled fluticasone propionate in healthy volunteers Br $\mathcal{F}$ Clin Pharmacol 1994;38:521-5.

12 Borgstrom L, Bondessan E, Moren F, Trofast E, Newman SP. Lung deposition of budesonide inhaled via Turbohaler: a comparison with terbutaline sulphate in normal subjects. Eur Respir 7 1994;7:69-73.

13 Hogger P, Rohdewald P. Binding kinetics of fluticasone propionate to the human glucocorticoid receptor. Steroids propionate to the

14 Boe J, Bakke P, Rodolen T, Skovlund E, Gulsvik A. High dose inhaled steroids in asthmatics: moderate efficacy gain dose inhaled steroids in asthmatics: moderate efficacy gain and suppression of the hypothalamic-pituit
(HPA) axis. Eur Respir $\mathcal{f}$ 1994;7:2179-84.

15 Fabbri L, Burge PS, Croonenburgh L, Warlies F, Weeke B, Ciacca A, et al. Comparison of fluticasone propionate with beclomethasone dipropionate in moderate to sever asthma treated for one year. Thorax 1993;48:817-23.

16 Ayres JG, Bateman ED, Lundback B, Harris TAJ. High dose fluticasone propionate, $1 \mathrm{mg}$ daily, versus fluticasone propionate, $2 \mathrm{mg}$ daily, or budesonide, $1.6 \mathrm{mg}$ daily, in patients with chronic severe asthma. Eur Respir $\mathcal{F} 1995 ; 8$ patients

17 Lipworth BJ. Clinical pharmacology of corticosteroids in bronchial asthma. Pharmacol Therap 1993;58:173-209.

8 Bain BM, Harrison G, Jenkins KD, Pateman AJ, Shenoy EVB. A sensitive radioimmunoassay, incorporating solidphase extraction, for fluticasone 17-propionate in 